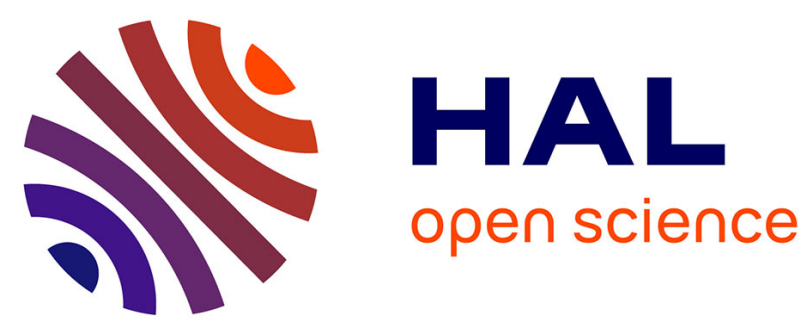

\title{
Recessive marfanoid syndrome with herniation associated with a homozygous mutation in Fibulin-3
}

Sami Bizzari, Lara El-Bazzal, Pratibha Nair, Antoine Younan, Samantha Stora, Cybel Mehawej, Stephany El-Hayek, Valérie Delague, André Mégarbané

\section{- To cite this version:}

Sami Bizzari, Lara El-Bazzal, Pratibha Nair, Antoine Younan, Samantha Stora, et al.. Recessive marfanoid syndrome with herniation associated with a homozygous mutation in Fibulin-3. European Journal of Medical Genetics, 2020, 63 (5), pp.103869. 10.1016/j.ejmg.2020.103869 hal-02550686

\section{HAL Id: hal-02550686 \\ https://hal-amu.archives-ouvertes.fr/hal-02550686}

Submitted on 25 Feb 2021

HAL is a multi-disciplinary open access archive for the deposit and dissemination of scientific research documents, whether they are published or not. The documents may come from teaching and research institutions in France or abroad, or from public or private research centers.
L'archive ouverte pluridisciplinaire HAL, est destinée au dépôt et à la diffusion de documents scientifiques de niveau recherche, publiés ou non, émanant des établissements d'enseignement et de recherche français ou étrangers, des laboratoires publics ou privés.

\section{(1) (1) $\$$}

Distributed under a Creative Commons Attribution - NonCommercial - NoDerivatives 44.0 


\title{
Recessive marfanoid syndrome with herniation associated with a homozygous mutation in Fibulin-3
}

\author{
Sami Bizzari ${ }^{\mathrm{a}}$, Lara El-Bazzal ${ }^{\mathrm{b}}$, Pratibha Nair ${ }^{\mathrm{a}}$, Antoine Younan ${ }^{\mathrm{c}}$, Samantha Stora ${ }^{\mathrm{d}}$, \\ Cybel Mehawej $^{\mathrm{f}}$, Stephany El-Hayek ${ }^{\mathrm{a}}$, Valerie Delague ${ }^{\mathrm{b}}$, André Mégarbané ${ }^{\mathrm{d}, \mathrm{e}, *}$ \\ ${ }^{\text {a }}$ Centre for Arab Genomic Studies, Dubai, United Arab Emirates \\ ${ }^{\mathrm{b}}$ Aix Marseille Univ, Inserm, MMG, U 1251, Marseille, France \\ ${ }^{\mathrm{c}}$ Surgery Department, Bellevue Hospital, Lebanon \\ ${ }^{\mathrm{d}}$ Institut Jérôme Lejeune, CRB BioJeL, Paris, France \\ ${ }^{\mathrm{e}}$ INOVIE-MENA, Beirut, Lebanon \\ ${ }^{\mathrm{f}}$ Saint Joseph University, Beirut, Lebanon
}

\begin{abstract}
A B S T R A C T
We have previously reported on a consanguineous family where 2 siblings, a girl and a boy, presented with tall stature, long and triangular faces, prominent forehead, telecanthus, ptosis, everted lower eyelids, downslanting palpebral fissures, large ears, high arched palate, long arm span, arachnodactyly, advanced bone age, joint laxity, pectus excavatum, inguinal hernia, and myopia, suggestive of a new subtype of connective tissue disorder (Megarbane et al. AJMG, 2012; 158(A)5: 1185-1189). On clinical follow-up, both patients had multiple inguinal, crural, and abdominal herniae, intestinal occlusions, several huge diverticula throughout the gut and the bladder, and rectal prolapse. In addition, the girl had a mild hearing impairment, and the boy a left diaphragmatic hernia.

Here we describe the molecular characterization of this disorder using Whole Exome Sequencing, revealing, in both siblings, a novel homozygous missense variant in the EFEMP1 gene, c.163T > C; p.(Cys55Arg) whose homozygous by descent, autosomal recessive transmission was confirmed through segregation analysis by Sanger sequencing. In addition, the girl exhibited a homozygous mutation in the MYO3A gene, c.1370_1371delGA; p.(Arg457Asnfs*25), associated with non-syndromic deafness. The siblings were also found to harbor a homozygous nonsense variant in the VCPKMT gene. We review the literature and discuss our updated clinical and molecular findings that suggest EFEMP1 to be the probable candidate gene implicated in this novel connective tissue disease.
\end{abstract}

\section{Introduction}

The extracellular matrix (ECM) comprises a dynamic framework of macromolecules involved in the structural support of the organs, tissues, and cells it surrounds, as well as a multitude of essential biochemical and mechanotransduction cell signaling processes (Hynes, 2009). Heritable connective tissue disorders (CTD) encompass a large number of clinically and genetically heterogeneous systemic diseases, mainly caused by dysfunction in the fibrous structural and organizational components of the ECM and their regulators (Bateman et al., 2009).

Two Lebanese siblings were previously described with a constellation of symptoms resembling features of CTD (Megarbane et al., 2012). Lack of particular features including ectopia lentis, skin bruising and hyperelasticity, tissue fragility, and cardiovascular symptoms rendered a Marfan syndrome or any subtype of Ehlers-Danlos syndrome diagnosis unlikely (Pepe et al., 2016; Joseph et al., 2018). Additionally, arrayCGH as well as Sanger sequencing of candidate genes implicated in CTD and overgrowth syndromes had previously failed to identify a genetic defect in this family (Megarbane et al., 2012).

In search for a genetic component, Whole Exome Sequencing (WES) was performed on these patients and possible gene associations with the phenotype were reviewed. We report on updated clinical findings as well as molecular characterization of this rare disorder with the identification of a novel homozygous missense mutation in EFEMP1 (EGFContaining Fibulin-Like Extracellular Matrix Protein 1) (p.Cys55Arg). We additionally report on a nonsense mutation in VCPKMT (Valosin Containing Protein Lysine (K) Methyltransferase) (p.Tyr33*), as well as

\footnotetext{
* Corresponding author. Institut Jérôme Lejeune. Paris, France.

E-mail address: andre.megarbane@institutlejeune.org (A. Mégarbané).
} 



\section{Unaffected mother III.1 (heterozygous carrier)}

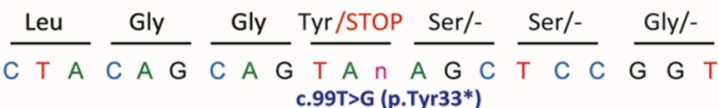
1

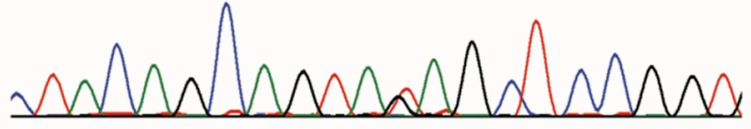

\section{Control}

$\frac{\text { Leu }}{C \text { T A }} \frac{\text { Gly }}{C A G} \frac{\text { Gly }}{\text { C A G }} \frac{\text { Tyr }}{\text { TA T }} \frac{\text { Ser }}{A G C} \frac{\text { Ser }}{\text { T C C }} \frac{\text { Gly }}{G \text { G T }}$

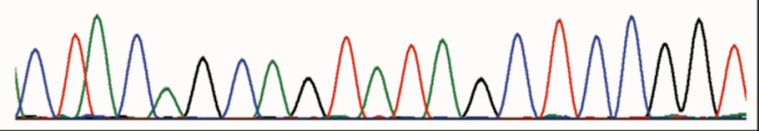

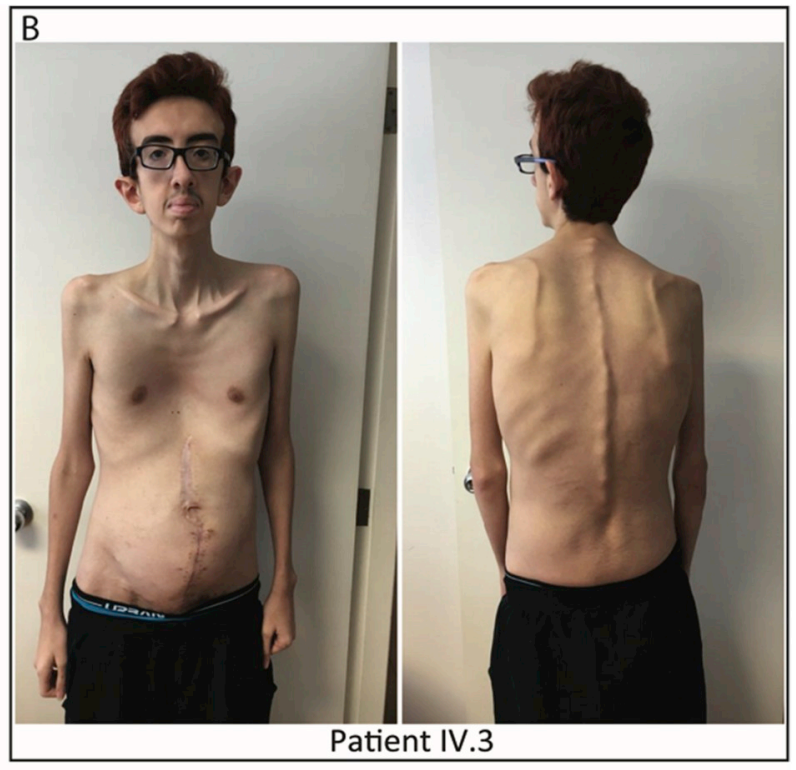

D Variation in EFEMP1

Affected patient IV.3 (homozygous)

$\frac{\text { Pro }}{C \text { C A }} \frac{\text { Asp }}{G A C} \frac{\text { Ala }}{G C T} \frac{\text { Arg }}{C G T} \frac{\text { Lys }}{A \text { A A }} \frac{\text { Gly }}{G G T} \frac{\text { Gly }}{G G A}$ c.163T>C (p.Cys55Arg)

1

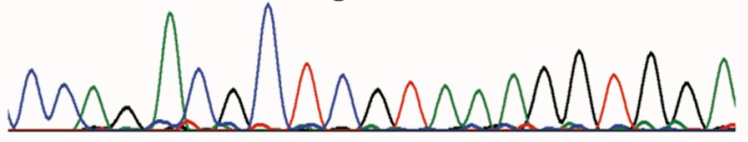

Unaffected mother III.1 (heterozygous carrier)

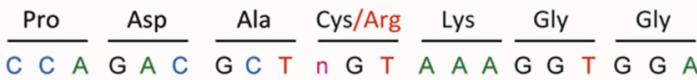
c.163T>C (p.Cys55Arg) $\downarrow$

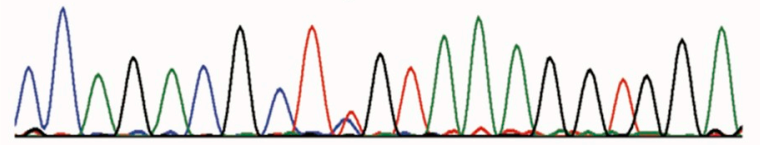

\section{Control}

$\frac{\text { Pro }}{\text { C C A }} \frac{\text { Asp }}{G \text { A C }} \frac{\text { Ala }}{G C T} \frac{\text { Cys }}{\text { T G T }} \frac{\text { Lys }}{\text { A A A }} \frac{\text { Gly }}{G G T} \frac{\text { Gly }}{G G A}$

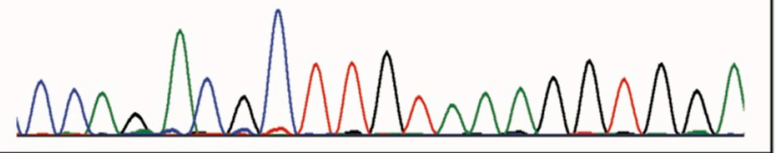

Fig. 1. Pedigree of the studied family. Filled symbols indicate affected individuals for both EFEMP1 and VCPKMT variants. Half-filled symbols indicate healthy carriers for both EFEMP1 and VCPKMT variants. 'U' Symbol indicates untested individuals. (B) Photographs of patient IV.3 showing the marfanoid habitus, pectus excavatum, and distended herniated stomach. (C-D) Chromatograms from the patient (IV.3), one parent (III.1) and a control showing the homozygous mutations detected in the family; (C) c.163T > C (p.Cys55Arg) missense mutation in EFEMP1 (NM_001039348) and (D) c.99T > G (p.Tyr33*) nonsense mutation in the VCPKMT gene (NM_024558).

a nonsense mutation in MYO3A (Myosin IIIA) (p.Arg457Asnfs*25) associated with the onset of progressive hearing loss in one of the siblings.

\section{Clinical report}

Two Lebanese siblings, a sister and a brother, born to healthy firstcousins parents, were previously seen at the clinic at ages 10 and 5 years respectively (patients IV.1 and IV.3; Fig. 1A; Megarbane et al., 2012; 158(A)5:1185-1189). Briefly, they exhibited an asthenic body habitus, tall stature (Z-score $\geq 2.9 \mathrm{SD}$ ), advanced bone age, long and triangular faces, prominent forehead, telecanthus, ptosis, everted lower eyelids, downslanting palpebral fissures, large ears, high arched palate, long arm span, arachnodactyly, positive thumb sign, joint laxity, pectus excavatum, inguinal hernia, and myopia. These features were 


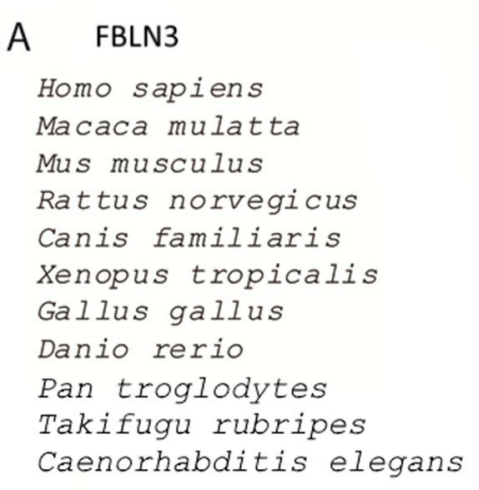

\section{MYO3A}

Homo sapiens

Pan troglodytes

Macaca mulatta

Felis catus

Mus musculus

Gallus gallus

Takifugu rubripes

Danio rerio

Drosophila melanogaster

Caenorhabditis elegans

Xenopus tropicalis

$\begin{array}{ll} & \text { B METLL21 } \\ \text { DIDECDIVPDACKGGM } & \text { Homo sapiens } \\ \text { DIDECDIVPDACKGGM } & \text { Macaca mulatta } \\ \text { DIDECDIVPDACKGGM } & \text { Mus musculus } \\ \text { DIDECDIVPDACKGGM } & \text { Rattus norvegicus } \\ \text { DIDECDIVPDACKGGM } & \text { Canis familiaris } \\ \text { DIDECEIVPDACKGGM } & \text { Xenopus tropicalis } \\ \text { DIDECEIVHDACKGGM } & \text { Gallus gallus } \\ \text { DIDECVLVSDACKAGM } & \text { Danio rerio }\end{array}$

DIDECDIVPDACKGGM

DIDECSLIDDACKGGM

DVDECNLGSHDCGPLY
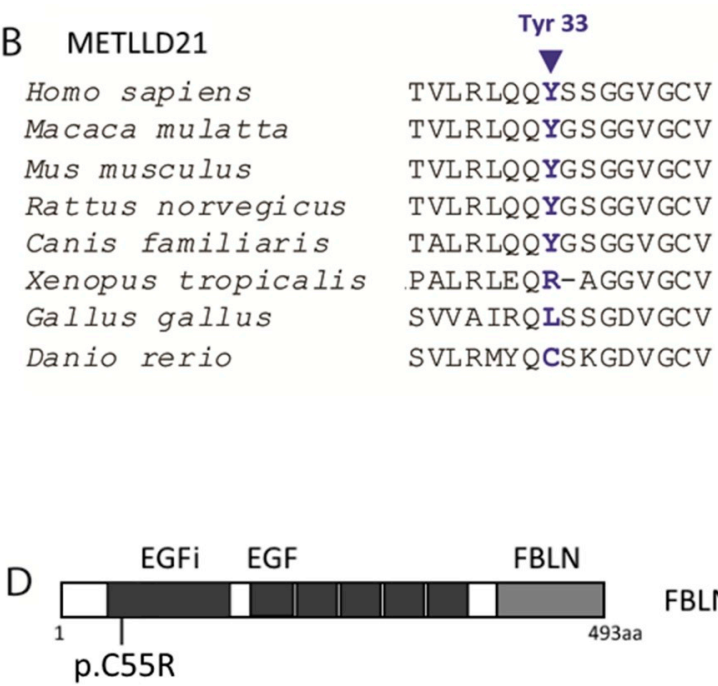

FBLN3

LTVLGKANNRTLQEKI

LTVLGKANNRTLQEKI

LTVLGKANNRTLQEKI

LTVLGKANNRTLQEKI

LTVLGKANNRTLQEKI

LTVLGKANNRTLQEKI

LTVLGKANNRSLQEKI

LTVLGKANNRTLQEKI

LCYLGD-GNRGATGRV

ILSSSVSNN-TIGDCV

LTVLGKANNRTLQEKI
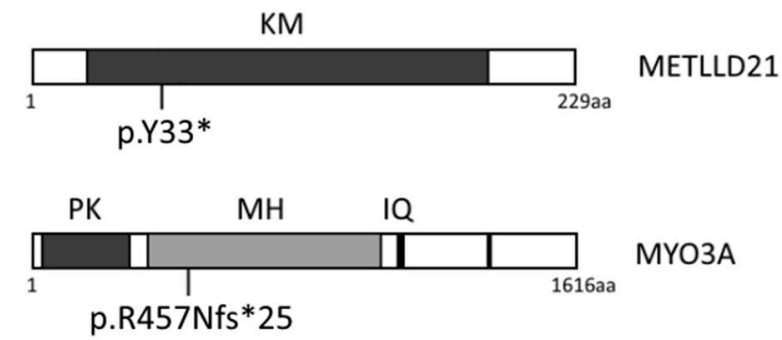

Fig. 2. Alignment of FBLN3 (NP_001034437) (B) METTL21D (NP_001035752), and (C) MYO3A (NP_059129) amino acid sequences of the protein regions comprising the mutations under investigation between different species. Colored residues are highly conserved across mammals. (D) Simplified schematic representation of Fibulin-3, METTL21D, and Myosin IIIA proteins showing protein domains and position of the variants identified in this study. EGFi: calcium binding epidermal growth factor like domain with large insertion between two Cys-Cys disulphide loops. EGF: calcium binding epidermal growth factor like domain. FBLN: Fibulin-type module. KM: Lysine methyltransferase. MH: Myosin head (motor) domain. IQ: IQ calmodulin-binding motif.

suggestive of a new subtype of CTD (Megarbane et al., 2012).

The sister, patient IV.1 was reexamined at age 19. Since her last examination, she was operated for bilateral ptosis and had developed bilateral mild hearing impairment at 14 years of age. At age 15, she was operated for cystorectocele secondary to pelvic floor laxity. A year later, she had breast implants for severe breast ptosis. At age 17, she was again operated for intestinal occlusion secondary to obstruction at the level of sigmoid colon. Work-up showed acute diverticulitis with stenosis. She was operated for a diversion colostomy. At examination, her height was $180 \mathrm{~cm}$ (Z-score: 2.6SD); head circumference (OFC) $58 \mathrm{~cm}$ (Z-score > 1.8SD; $>1.8 \mathrm{SD}$ at age 10 ); and weight $86 \mathrm{~kg}$ (Z-score: $1.8 \mathrm{SD} ; 2.5 \mathrm{SD}$ at age 10$)$. A month later, she was operated, by laparoscopy single port technique, for resection of the diseased sigmoid. During the operation, diffused diverticular disease that extended from the stomach, the small intestine, to the upper rectum was noted. She underwent resection of the stenotic and diverticular sigmoid with mechanical colorectal anastomosis. Post-operative course was uneventful. Ten months later she was operated for a huge ventral hernia at the single port trocar surgery site. Heart and neurological examinations were normal. Ophthalmological examination was normal except for the presence of high myopia.

The affected brother, patient IV.3, was followed up at age 14 in the clinic (Fig. 1B). At the time of examination, his height was $183 \mathrm{~cm}$ (Zscore: $2.4 \mathrm{SD}$ ); OFC $56.5 \mathrm{~cm}$ (Z-score > 1.2SD; >1.2SD at age 5); and weight $62 \mathrm{~kg}$ (Z-score: $0.9 \mathrm{SD} ; 1.5 \mathrm{SD}$ at age 7 ). His chest circumference was $87 \mathrm{~cm}$ (Z-score $>1.6 \mathrm{SD}$ ). He presented similar, but more severe symptoms to his affected sister. Since the age of 10 , he was operated for multiple inguinal, crural, and abdominal herniae, and was admitted several times for recurrent intestinal occlusions. One of the episodes needed laparoscopy exploration which showed several pseudo- diverticula extended from the stomach to the terminal ileum with intestinal pneumatosis and several diverticula that were perforated with peritoneal cavity pneumatosis. Huge diverticula on the wall of the stomach was noted as well. He also had an obstructive intestinal volvulus at the mid ileum with multiple herniae on the abdominal wall with internal obturator hernia and left inguinal hernia. Four months later he was operated for a resection of a huge diverticula of the bladder. A few months later, he was operated for a left diaphragmatic hernia, and another recurrent bilateral inguinal hernia and abdominal herniae with rectal prolapse, and then for a severe perineal hernia where a large portion of the urinary bladder was herniated through the right pelvic floor muscles into the right ischiorectal and ischioanal fossa. He exhibited recurrent episodes of diarrhea, vomiting, and abdominal pain,. Pectus excavatum was more prominent and he additionally exhibited mild right convex dorsal scoliosis, and high myopia.

Clinical examination of the parents and healthy sibling including anthropometric measurements, as well as ophthalmological and cardiac examinations were normal.

\section{Molecular report}

This study was approved by the institutional ethics review board. 3-5 $\mathrm{ml}$ whole blood samples were obtained from the two siblings upon informed consent and genomic DNA was extracted for WES. The boosted exome test using the TruSeq SBS v3 kit and HiSeq 2000 platform (Illumina, San Diego, CA, US) by Invitae (San Francisco, CA, US) was used, covering approximately $95 \%$ of the exome and 10bp of intron-exon boundaries at a mean depth coverage of $267 x$ and minimum depth coverage of $\geq 20 \mathrm{x}$ per base. Variant selection processes used in 
miterıng tnese variants included $\mathrm{MAF}<1 \%$, pathogenicity, genomic position, quality, family history, and literature review; 940 genes associated with Human Phenotype Ontology clinical terms described in both siblings were additionally reviewed.

Variant filtration revealed a homozygous missense transition in the EFEMP1 gene, NM_001039348.2: c.163T > C; p.(Cys55Arg) and a homozygous nonsense transversion in the VCPKMT gene, NM_024558.2: c.99T > G; p.(Tyr33*) in both siblings. These two variants were confirmed through sanger sequencing in both patients and found to be in the heterozygous state in the healthy brother and parents (Fig. 1C and D). The former mutation replaces a phylogenetically conserved cysteine residue in the first $\mathrm{N}$-terminal epidermal growth factor (EGF)-like domain of the Fibulin-3 protein and the latter mutation causes an early truncation in the lysine methyltransferase protein METTL21D (Fig. 2A,B,D). Using Combined Annotation Dependent Depletion (CADD) software, both mutations were predicted to be deleterious with high Phred-like scaled C-scores of 28.3 and 34 for the variants identified in EFEMP1 and VCPKMT respectively (https://cadd. gs.washington.edu/). Neither of these variants were reported in the heterozygous or homozygous state in public databases including dbSNP, gnomAD, ClinVar and 1000G.

A homozygous $2 \mathrm{bp}$ deletion resulting in frameshift and termination in the MYO3A gene NM_017433.4: c.1370_1371delGA; p. (Arg457Asnfs*25) was additionally identified in patient IV.1. CADD software predicts the latter variant to be disease causing with a Phredlike scaled C-score of 34 . This variant is reported in the heterozygous state in gnomAD with an allele frequency of $0.001 \%$ (3 alleles in 3 adults of European origin out of 249394 alleles; rs760866131) and occurs at a conserved residue in the motor domain of the Myosin IIIA protein (Fig. 2C and D). This variant was not reported in ClinVar.

The EFEMP1 and MYO3A variants were checked for in the Saudi Human Genome Program database which contains over 14000 patientderived genetic variants; neither of these variants have been reported (https://genomics.saudigenomeprogram.org/en/researchers/\#dbaccess) (Abouelhoda et al., 2016). Clinical and molecular details of the described patients were summarized in Table 1.

\section{Discussion}

We report on a consanguineous Lebanese family exhibiting a novel connective tissue syndrome. Hallmark clinical manifestations in the two affected siblings involved multiple and recurrent herniae, pelvic and rectal prolapse, huge diverticula, marfanoid habitus, joint laxity, dorsal scoliosis, advanced bone age, pectus excavatum, dysmorphic facial features, and myopia. WES and in silico analysis pointed to EFEMP1 as the probable candidate gene implicated in this autosomal recessive disorder. We additionally report on a mutation in the MYO3A gene that is likely causative of nonsyndromic progressive hearing loss.

EFEMP1 encodes Fibulin-3, a member of eight conserved secreted ECM basement membrane glycoproteins (MIM\# 601548) (Hanada and Sasaki, 2018). Short fibulins including fibulin-3/-4/-5 have evolved into the specialized function of elastic fiber (EF) assembly and homeostasis. Fibulin-4 and fibulin-5 are essential in the structural and organizational assembly of EF through their interactions with ECM components that form, deposit, and merge elastin with the microfibril scaffold (Yanagisawa and Davis, 2010). Fibulin-3 is expressed widely in adult tissues (abundant in eye, fascia, skin and vasculature) and is predominant in basement membrane epithelial, endothelial, and fibroblast cells; it interacts with various ECM components and is thought to be involved in basement membrane integrity and EF maintenance rather than assembly (Zhang and Marmorstein, 2010).

Reported heritable disease associated with EFEMP1 (Doyne's Honeycomb Retinal Dystrophy/Malattia Leventinese; MIM\# 126600) involves characteristic formation of drusen (yellow-white deposits) in the posterior pole region of the eye during early adulthood, leading to progressive and severe vision loss with macular and retinal degeneration; this is attributed to a single autosomal dominant mutation p.(Arg345Trp) (rs121434491) (Hulleman, 2016). There is one instance of recessive transmission reported in offspring of affected heterozygous parents, which was associated with a relatively more severe ocular phenotype, corroborating the dominant toxic gain of function effect of the mutation (Fu et al., 2007). Eye-related features reported in the patients in this study included ptosis and myopia with no evidence of drusen formation or macular degeneration. Mouse models exhibiting the EFEMP1 p.(Arg345Trp) mutation developed sub-retinal pigment epithelium (RPE) deposits and presented with cardinal features of Malattia Leventinese and age-related macular dystrophy (Stanton et al., 2017; Marmorstein et al., 2007), whereas knockout (EFEMP1 ${ }^{-/-}$) mice lacked these deposits and were resistant to its formation under induced conditions (Zayas-Santiago et al., 2017).

Strikingly, multiple studies on EFEMP1-/- mice revealed a phenotypic resemblance to the siblings reported here (Table 1). The hallmark findings in these mice involved severe herniation (in the C57BL/6 strain), in addition to early aging, reduced bone density and lordokyphosis, pelvic and rectal prolapse, reproductive impairment, generalized muscle, fat, and organ atrophy, reduced body mass, loose skin, and hair thinning (McLaughlin et al., 2007; Rahn et al., 2009). The herniated mice exhibited multiple sites of direct and indirect large inguinal hernia as well as xiphoid process protrusions; all EFEMP1 ${ }^{-/-}$mice died at a significantly earlier age relative to wild type mice, with multiple phenotypes including atrophic features, reduced body size/mass, and loose skin attributed to expected, albeit premature, consequences of aging in mice comparable to human aging. The asthenic appearance and thinness described in both patients can be compared to the atrophic (muscle and fat) features and reduced body size in the mice. In the patients' original clinical analysis 9 years prior, no skin manifestations were reported with noted absence of hyperelasticity, scarring, and redundant skin expected in CTD; however patient IV.1 has developed severe breast ptosis indicating loss of skin elasticity. CTDs including Marfan syndrome and Ehlers-Danlos syndrome have been associated with hernia predisposition (Harrison et al., 2016). Hypomorphic mouse models of Marfan syndrome (Fibrillin-1) were shown to exhibit diaphragmatic hernia associated with severe kyphosis, scoliosis, as well as rib -and to a lesser degree long bone-overgrowth; however pulmonary and severe vascular features lead to early death (Schwill et al., 2013). While no obvious skeletal defects or other systemic features were identified in EFEMP1 $1^{-/-}$mice, they exhibited severe kyphosis and reduced bone density (McLaughlin et al., 2007). Our patients exhibited musculoskeletal features including advanced bone age, pectus excavatum (rib-cage deformity), scoliosis (Patient IV.3), and joint laxity indicating a role of Fibulin-3 in bone and cartilage. Fibulin-3 is expressed in condensing mesenchymal cells and is involved in skeletal and cartilaginous development at the embryonic stage (Ehlermann et al., 2003). In studies on mouse models of osteoarthritis, severely reduced Fibulin-3 expression in articular cartilage with increasing age correlated with disrupted cartilage integrity. This is thought to be due to Fibulin-3's involvement in inhibiting chondrocyte differentiation, with healthy immature chondrocytes being a property of healthy cartilage in joints (Hasegawa et al., 2017). In EFEMP1 ${ }^{-/-}$mice, a severe reduction in EFs specifically in fascia connective tissue (e.g. transverse and superficial fascia), and much less so in other tissues, including the lung, skin (dermal EF), and aorta, was reported as the main pathology. The localized pathogenic effect in fascia tissue of EFEMP1 $1^{-/-}$mice may explain the prominence of various types of hernias and lack of multiple systemic CTD features in our patients, and suggests a possible loss-offunction effect of the p.(Cys55Arg) mutation. Functional studies are required to establish the deleterious effect of the reported mutation.

Fibulins exhibit tandem repeats of calcium binding EGF-like domains. These domains exhibit six conserved cysteine residues which form disulphide bond loops. The homozygous missense variant we report in EFEMP1 p.(Cys55Arg) likely disrupts the disulphide bond in the first N-terminal atypical calcium binding EGF-like domain, and is 


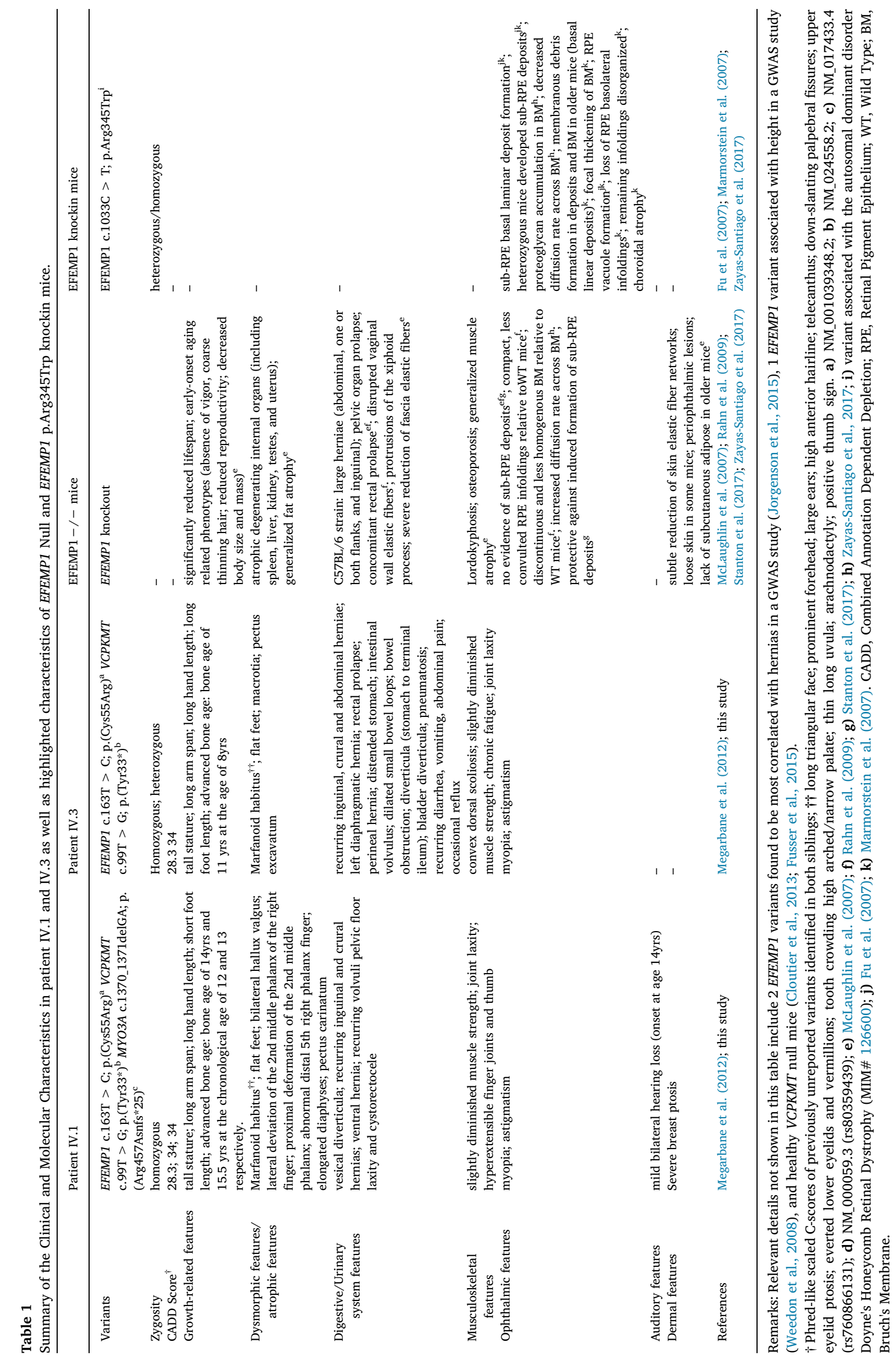


predicted to be deleterious using in silico tools.

The exact molecular function of Fibulin-3 remains unclear. Fibulin-3 is thought to antagonize ECM enzyme activity by promoting expression of tissue inhibitors of metalloproteinases TIMP-3/-1 and inhibiting expression of matrix metalloproteinases MMP-2/-3/-9, leading to homeostatic protection against elastic fiber and collagen degradation (Zhang and Marmorstein, 2010). EFEMP1 along with tumor-suppressor protein WT1 were found to be most highly expressed in mouse connective tissue identical to human transversalis fascia, the protrusion site of inguinal hernias (Jorgenson et al., 2015). Causal network analysis in the latter study highlighted common interaction between these two proteins with TIMP3; WT1 is thought to activate TIMP-3, which Fibulin3 binds in turn to potentially amplify its inhibitory activity on proteolytic ECM enzymes. This function is further supported by studies of p.Arg345Trp EFEMP1 knockin mice which exhibited inhibited proteoglycenase (MMPs) activity in Bruch's membrane, the potential root of deposit formation located underneath the RPE (Zayas-Santiago et al., 2017). The retention of components in aberrant ECM is thought to elicit a complement system response which exacerbates deposit formation. Recent studies by one group have however showed conflicting results, between mouse and human RPE cell cultures, on the potential ECM enzyme inhibitory role of p.Arg345Trp Fibulin-3 and deposit formation (Fernandez-Godino et al., 2015, 2018). In a following study involving unaltered EFEMP1, the authors illustrate complement driven accumulation of collagen and inhibition of the ubiquitin proteasome pathway in human RPE cells; the latter is thought to impair ECM turnover with repression of TIMP-3 activity and increased aberrant MMP-2 activity compounding deposit formation (Fernandez-Godino and Pierce, 2018).

Genome wide association studies have linked various single nucleotide polymorphisms (SNPs) in EFEMP1 to a variety of phenotypes. Pertinent associations include multiple SNPs (rs2009262 and rs11899888) exhibiting the highest association to the formation of direct and indirect inguinal hernias (Jorgenson et al., 2015). In another study, the rs3791675 SNP in EFEMP1 was one among 20 SNPs that explained approximately $3 \%$ of variation in height between two groups that expressed the least and most alleles associated with being tall respectively (Weedon et al., 2008). EFEMP1 SNPs also correlated with forced lung capacity, and other SNPs with opposing behavioral traits from harm avoidance to suicidal tendencies, thought to be due to a role of Fibulin-3 in neuroplasticity (Balestri et al., 2017; Loth et al., 2014).

Patient IV.1 was additionally shown to have a homozygous mutation p.(Arg457Asnfs*25) in MYO3A, which encodes Myosin IIIA, an actin-dependent cargo transport motor protein that binds and transports actin-bundling proteins to stereocilia actin filament tips to promote elongation. This process is required for the fine-tuned height organization of the stereocilia staircase (Ebrahim et al., 2016). Pathogenic variants in this gene were extensively reported to be the cause of bilateral progressive hearing loss that appears in the second decade or later (DFNB30; MIM\# 607101) (Dantas et al., 2018; Walsh et al., 2002). The variant we report potentially leads to a truncated protein devoid of its actin-binding site, and is predicted to be deleterious in silico. This mutation is highly likely to be responsible for the progressive non syndromic deafness exhibited by patient IV.1.

The siblings were also found to share a homozygous nonsense mutation p.(Tyr33*) in VCPKMT (MIM\# 615260), which encodes METTL21D, a lysine methyltransferase belonging to a recently characterized family (family 16) of 10 seven- $\beta$-strand methyltransferase members (Kernstock et al., 2012). METTL21D was shown to uniquely tri-methylate valosin containing protein (VCP), and this modification is thought to be indirectly enhanced by the GLUT4 VCP cofactor (Fusser et al., 2015). The variant identified here purportedly causes an early truncation in METTL21D, abolishing S-adenosyl-methionine binding sites, and is predicted in silico to be deleterious. The methylation status of VCP however reportedly seems to have no effect on health; VCPKMT knockout mice were shown to be healthy and fertile, exhibiting no pathogenic phenotype (Fusser et al., 2015). VCP is an ATPase involved in ubiquitous cellular functions including ubiquitin-dependent protein degradation, transcription factor regulation, cell-cycle regulation and DNA damage response; dominant mutations in VCP have been associated with neurodegenerative disorders including inclusion body myopathy associated with Paget's disease (MIM\# 167320), likely caused by dysregulated ATPase activity (Halawani et al., 2009), as well as Amyotrophic Lateral Sclerosis (MIM\# 613954) (Johnson et al., 2010) and axonal Charcot-Marie-Tooth disease (MIM\# 616687) (Gonzalez et al., 2014). Although in vitro studies have showed decreased ATPase activity of VCP due to methylation of a Walker B motif of the first ATPase domain by METTL21D, in vivo studies on VCPKMT knockout mice did not show an increase in ATPase activity (Cloutier et al., 2013; Fusser et al., 2015). VCPKMT overexpression was studied for an as of yet unclear involvement in cancer metastasis (Kernstock et al., 2012; Thiele et al., 2011). Taking together these studies and the clinical description of our patients, the nonsense VCPKMT mutation is unlikely to contribute to the disease phenotype we describe.

In conclusion, we describe a new autosomal recessive disorder likely associated with a missense mutation in Fibulin-3, predicted to be deleterious in silico, in two Lebanese patients exhibiting a phenotype of connective tissue disease; in addition to the unrelated onset of progressive non syndromic deafness likely caused by a truncating mutation in Myosin IIIA. WES is critical in the reporting of rare disease-causing variants in the clinical scene and is especially important in consanguineous populations such as in Lebanon. Although inbred families are suited for the molecular diagnosis of rare mendelian disorders, limited segregation analysis in small families may fail to pinpoint deleterious variants when more than one potential causal mutation is identified. The identification of bi-allelic EFEMP1 variants in other patients with comparable symptoms would confirm this gene as disease causing.

\section{Addendum}

During the review and acceptance of this manuscript, an article was published in the European Journal of Human Genetics entitled "Biallelic variants in EFEMP1 in a man with a pronounced connective tissue phenotype" (Driver et al., 2019). This paper describes truncating EFEMP1 variants in an individual in association with a starkly similar phenotype to the patients reported here. This further confirms the deleterious effect of loss-of-function variants in EFEMP1 and its association with a connective tissue and herniation phenotype. It is noteworthy that the clinical phenotype of this disorder was originally described by Megarbane et al. (2012).

\section{Funding}

No funding was received.

\section{CRediT authorship contribution statement}

Sami Bizzari: Writing - original draft, Writing - review \& editing, Formal analysis. Lara El-Bazzal: Writing - review \& editing, Formal analysis. Antoine Younan: Writing - original draft, Writing - review \& editing, Formal analysis. Stephany El-Hayek: Writing - original draft, Writing - review \& editing, Formal analysis. Valerie Delague: Writing original draft, Writing - review \& editing, Formal analysis. André Mégarbané: Writing - original draft, Writing - review \& editing.

\section{Declaration of competing interest}

Authors declare no competing financial interests in relation to the work described in this paper. 


\section{Acknowledgements}

We are thankful to the family for their cooperation despite the physical and emotional burden of the disorder they are experiencing.

\section{References}

Abouelhoda, M., Faquih, T., El-Kalioby, M., Alkuraya, F.S., 2016. Revisiting the morbid genome of Mendelian disorders. Genome Biol. 17 (1), 235. https://doi.org/10.1186/ s13059-016-1102-1.

Balestri, M., Crisafulli, C., Donato, L., Giegling, I., Calati, R., Antypa, N., ... Rujescu, D., 2017. Nine differentially expressed genes from a post mortem study and their association with suicidal status in a sample of suicide completers, attempters and controls. J. Psychiatr. Res. 91, 98-104. https://doi.org/10.1016/j.jpsychires.2017.03. 009.

Bateman, J.F., Boot-Handford, R.P., Lamande, S.R., 2009. Genetic diseases of connective tissues: cellular and extracellular effects of ECM mutations. Nat. Rev. Genet. 10 (3), 173-183. https://doi.org/10.1038/nrg2520.

Cloutier, P., Lavallee-Adam, M., Faubert, D., Blanchette, M., Coulombe, B., 2013. A newly uncovered group of distantly related lysine methyltransferases preferentially interact with molecular chaperones to regulate their activity. PLoS Genet. 9 (1), e1003210. https://doi.org/10.1371/journal.pgen.1003210.

Dantas, V.G.L., Raval, M.H., Ballesteros, A., Cui, R., Gunther, L.K., Yamamoto, G.L., ... Mingroni-Netto, R.C., 2018. Characterization of a novel MYO3A missense mutatio associated with a dominant form of late onset hearing loss. Sci. Rep. 8 (1), 8706. https://doi.org/10.1038/s41598-018-26818-2.

Driver, S.G.W., Jackson, M.R., Richter, K., Tomlinson, P., Brockway, B., Halliday, B.J., ... Wade, E.M., 2019. Biallelic variants in EFEMP1 in a man with a pronounced connective tissue phenotype. Eur. J. Hum. Genet. https://doi.org/10.1038/s41431-0190546-. Epub ahead of print.

Ebrahim, S., Avenarius, M.R., Grati, M., Krey, J.F., Windsor, A.M., Sousa, A.D., ... Kachar, B., 2016. Stereocilia-staircase spacing is influenced by myosin III motors and their cargos espin-1 and espin-like. Nat. Commun. 7, 10833. https://doi.org/10.1038/ ncomms10833.

Ehlermann, J., Weber, S., Pfisterer, P., Schorle, H., 2003. Cloning, expression and characterization of the murine Efemp1, a gene mutated in Doyne-Honeycomb retinal dystrophy. Gene Expr. Patterns 3 (4), 441-447.

Fernandez-Godino, R., Bujakowska, K.M., Pierce, E.A., 2018. Changes in extracellular matrix cause RPE cells to make basal deposits and activate the alternative complement pathway. Hum. Mol. Genet. 27 (1), 147-159. https://doi.org/10.1093/hmg/ ddx392.

Fernandez-Godino, R., Garland, D.L., Pierce, E.A., 2015. A local complement response by RPE causes early-stage macular degeneration. Hum. Mol. Genet. 24 (19), 5555-5569. https://doi.org/10.1093/hmg/ddv287.

Fernandez-Godino, R., Pierce, E.A., 2018. C3a triggers formation of sub-retinal pigment epithelium deposits via the ubiquitin proteasome pathway. Sci. Rep. 8 (1), 9679 https://doi.org/10.1038/s41598-018-28143-0.

Fu, L., Garland, D., Yang, Z., Shukla, D., Rajendran, A., Pearson, E., ... Pierce, E.A., 2007. The R345W mutation in EFEMP1 is pathogenic and causes AMD-like deposits in mice. Hum. Mol. Genet. 16 (20), 2411-2422. https://doi.org/10.1093/hmg/ddm198.

Fusser, M., Kernstock, S., Aileni, V.K., Egge-Jacobsen, W., Falnes, P.O., Klungland, A., 2015. Lysine methylation of the valosin-containing protein (VCP) is dispensable for development and survival of mice. PloS One 10 (11), e0141472. https://doi.org/10. 1371/journal.pone.0141472.

Gonzalez, M.A., Feely, S.M., Speziani, F., Strickland, A.V., Danzi, M., Bacon, C., ... Shy, M.E., 2014. A novel mutation in VCP causes Charcot-Marie-Tooth Type 2 disease. Brain 137 (Pt 11), 2897-2902. https://doi.org/10.1093/brain/awu224.

Halawani, D., LeBlanc, A.C., Rouiller, I., Michnick, S.W., Servant, M.J., Latterich, M., 2009. Hereditary inclusion body myopathy-linked p97/VCP mutations in the NH2 domain and the D1 ring modulate p97/VCP ATPase activity and D2 ring conformation. Mol. Cell Biol. 29 (16), 4484-4494. https://doi.org/10.1128/mcb.00252-09.

Hanada, K., Sasaki, T., 2018. Expression and purification of recombinant fibulins in mammalian cells. Methods Cell Biol. 143, 247-259. https://doi.org/10.1016/bs.mcb. 2017.08.014.

Harrison, B., Sanniec, K., Janis, J.E., 2016. Collagenopathies-implications for abdominal wall reconstruction: a systematic review. Plast. Reconstr. Surg. Glob. Open 4 (10), e1036. https://doi.org/10.1097/gox.0000000000001036.

Hasegawa, A., Yonezawa, T., Taniguchi, N., Otabe, K., Akasaki, Y., Matsukawa, T., ... Lotz, M.K., 2017. Role of fibulin 3 in aging-related joint changes and osteoarthritis pathogenesis in human and mouse knee cartilage. Arthritis Rheum. 69 (3), 576-585. https://doi.org/10.1002/art.39963.

Hulleman, J.D., 2016. Malattia leventinese/doyne Honeycomb retinal dystrophy: similarities to age-related macular degeneration and potential therapies. Adv. Exp. Med. Biol. 854, 153-158. https://doi.org/10.1007/978-3-319-17121-0_21.

Hynes, R.O., 2009. The extracellular matrix: not just pretty fibrils. Science 326 (5957), 1216-1219. https://doi.org/10.1126/science.1176009.

Johnson, J.O., Mandrioli, J., Benatar, M., Abramzon, Y., Van Deerlin, V.M., Trojanowski, J.Q., ... Traynor, B.J., 2010. Exome sequencing reveals VCP mutations as a cause of familial ALS. Neuron 68 (5), 857-864. https://doi.org/10.1016/j.neuron.2010.11. 036.

Jorgenson, E., Makki, N., Shen, L., Chen, D.C., Tian, C., Eckalbar, W.L., ... Avins, A., 2015. A genome-wide association study identifies four novel susceptibility loci underlying inguinal hernia. Nat. Commun. 6, 10130. https://doi.org/10.1038/ncomms10130.

Joseph, A.W., Joseph, S.S., Francomano, C.A., Kontis, T.C., 2018. Characteristics, diag nosis, and management of ehlers-danlos syndromes: a review. JAMA Facial Plast. Surg. 20 (1), 70-75. https://doi.org/10.1001/jamafacial.2017.0793.

Kernstock, S., Davydova, E., Jakobsson, M., Moen, A., Pettersen, S., Maelandsmo, G.M., ... Falnes, P.O., 2012. Lysine methylation of VCP by a member of a novel human protein methyltransferase family. Nat. Commun. 3, 1038. https://doi.org/10.1038/ ncomms2041.

Loth, D.W., Soler Artigas, M., Gharib, S.A., Wain, L.V., Franceschini, N., Koch, B., ... London, S.J., 2014. Genome-wide association analysis identifies six new loci associated with forced vital capacity. Nat. Genet. 46 (7), 669-677. https://doi.org/10. 1038/ng.3011.

Marmorstein, L.Y., McLaughlin, P.J., Peachey, N.S., Sasaki, T., Marmorstein, A.D., 2007. Formation and progression of sub-retinal pigment epithelium deposits in Efemp1 mutation knock-in mice: a model for the early pathogenic course of macular degeneration. Hum. Mol. Genet. 16 (20), 2423-2432. https://doi.org/10.1093/hmg/ ddm199.

McLaughlin, P.J., Bakall, B., Choi, J., Liu, Z., Sasaki, T., Davis, E.C., ... Marmorstein, L.Y., 2007. Lack of fibulin-3 causes early aging and herniation, but not macular degeneration in mice. Hum. Mol. Genet. 16 (24), 3059-3070. https://doi.org/10.1093/ $\mathrm{hmg} / \mathrm{ddm} 264$.

Megarbane, A., Hanna, N., Chouery, E., Jalkh, N., Mehawej, C., Boileau, C., 2012. Marfanoid habitus, inguinal hernia, advanced bone age, and distinctive facial features: a new collagenopathy? Am. J. Med. Genet. 158A (5), 1185-1189. https://doi. org/10.1002/ajmg.a.35279.

Pepe, G., Giusti, B., Sticchi, E., Abbate, R., Gensini, G.F., Nistri, S., 2016. Marfan syndrome: current perspectives. Appl. Clin. Genet. 9, 55-65. https://doi.org/10.2147/ tacg.s96233.

Rahn, D.D., Acevedo, J.F., Roshanravan, S., Keller, P.W., Davis, E.C., Marmorstein, L.Y., Word, R.A., 2009. Failure of pelvic organ support in mice deficient in fibulin-3. Am. J. Pathol. 174 (1), 206-215. https://doi.org/10.2353/ajpath.2009.080212.

Schwill, S., Seppelt, P., Grunhagen, J., Ott, C.E., Jugold, M., Ruhparwar, A., ... Kallenbach, K., 2013. The fibrillin-1 hypomorphic mgR/mgR murine model of Marfan syndrome shows severe elastolysis in all segments of the aorta. J. Vasc. Surg. 57 (6), 1628-1636. https://doi.org/10.1016/j.jvs.2012.10.007. 1636 e1621-1623.

Stanton, J.B., Marmorstein, A.D., Zhang, Y., Marmorstein, L.Y., 2017. Deletion of Efemp1 is protective against the development of sub-RPE deposits in mouse eyes. Invest. Ophthalmol. Vis. Sci. 58 (3), 1455-1461. https://doi.org/10.1167/iovs.16-20955.

Thiele, W., Novac, N., Mink, S., Schreiber, C., Plaumann, D., Fritzmann, J., ... Sleeman, J.P., 2011. Discovery of a novel tumour metastasis-promoting gene, NVM-1. J. Pathol. 225 (1), 96-105. https://doi.org/10.1002/path.2924.

Walsh, T., Walsh, V., Vreugde, S., Hertzano, R., Shahin, H., Haika, S., ... Avraham, K.B., 2002. From flies' eyes to our ears: mutations in a human class III myosin cause progressive nonsyndromic hearing loss DFNB30. Proc. Natl. Acad. Sci. U. S. A. 99 (11), 7518-7523. https://doi.org/10.1073/pnas.102091699.

Weedon, M.N., Lango, H., Lindgren, C.M., Wallace, C., Evans, D.M., Mangino, M., ... Frayling, T.M., 2008. Genome-wide association analysis identifies 20 loci that influence adult height. Nat. Genet. 40 (5), 575-583. https://doi.org/10.1038/ng.121.

Yanagisawa, H., Davis, E.C., 2010. Unraveling the mechanism of elastic fiber assembly: the roles of short fibulins. Int. J. Biochem. Cell Biol. 42 (7), 1084-1093. https://doi. org/10.1016/j.biocel.2010.03.009.

Zayas-Santiago, A., Cross, S.D., Stanton, J.B., Marmorstein, A.D., Marmorstein, L.Y., 2017. Mutant fibulin-3 causes proteoglycan accumulation and impaired diffusion across Bruch's membrane. Invest. Ophthalmol. Vis. Sci. 58 (7), 3046-3054. https:// doi.org/10.1167/iovs.17-21720.

Zhang, Y., Marmorstein, L.Y., 2010. Focus on molecules: fibulin-3 (EFEMP1). Exp. Eye Res. 90 (3), 374-375. https://doi.org/10.1016/j.exer.2009.09.018. 